\title{
Review article: tegaserod - the global experience
}

\author{
W. D. CHEY \\ Division of Gastroenterology, University of Michigan Medical Center, Ann Arbor, MI, USA
}

\section{SUMMARY}

Studies from the Western hemisphere have established the efficacy and safety of tegaserod in women with irritable bowel syndrome and constipation. This review summarizes the results of recent studies from around the world that confirm the efficacy and safety of tegaserod, and expand our understanding of the role of this drug in the treatment of patients with irritable bowel syndrome.

\section{INTRODUCTION}

An ideal treatment for patients with irritable bowel syndrome and constipation should target the underlying pathophysiology of the disorder and, in so doing, offer efficacy for the multiple symptoms of irritable bowel syndrome. Such a medication ideally should offer a rapid onset of action, sustained effectiveness, be devoid of significant adverse effects and reduce the socio-economic impact of irritable bowel syndrome.

Unfortunately, most of the 'traditional' therapies for irritable bowel syndrome and constipation (antispasmodics, fibre, tricyclic antidepressants, etc.) do not fulfil these idealized attributes. With few exceptions, these traditional therapies for irritable bowel syndrome and constipation have not been proven to be effective in rigorously designed randomized controlled trials. When therapies have shown benefit for irritable bowel syndrome, they have typically improved only individual symptoms (i.e. fibre for constipation) as opposed to the global consortium of symptoms that constitutes irritable bowel syndrome and constipation. ${ }^{1}$

Correspondence to: Dr W. D. Chey, Division of Gastroenterology, University of Michigan Medical Center, 3912 Taubman Center, Ann Arbor, MI 48109-0362, USA.

E-mail: wchey@umich.edu

\section{TEGASEROD FOR IRRITABLE BOWEL SYNDROME AND CONSTIPATION}

More recently, serotonin has been found to play an important role in gastrointestinal motor function, secretion and sensation. ${ }^{2}$ To date, seven different serotonin receptor subclasses have been identified. The 5- $\mathrm{HT}_{3}$ and $5-\mathrm{HT}_{4}$ receptor subclasses have been best characterized in the gastrointestinal tract. There is highquality evidence from well-designed randomized controlled trials that $5-\mathrm{HT}_{3}$ antagonists and $5-\mathrm{HT}_{4}$ agonists are effective for the treatment of specific subsets of irritable bowel syndrome patients. ${ }^{3}$ Tegaserod is a highly selective, partial $5-\mathrm{HT}_{4}$ receptor agonist. Through its effects at the $5-\mathrm{HT}_{4}$ receptor, tegaserod has a number of physiological effects. It stimulates the peristaltic reflex, resulting in the acceleration of intestinal and colonic transit. It also stimulates chloride secretion within the intestinal tract. Studies in animals and preliminary work in humans also suggest that tegaserod has effects on visceral sensation. ${ }^{4}$ Whether these effects on visceral sensation are a primary effect on afferent pathways or a secondary effect related to influences on motility and secretory function of the gut remains to be elucidated. The combined physiological effects of tegaserod make it an attractive candidate for the treatment of patients with irritable bowel syndrome and constipation. 


\section{PIVOTAL TRIALS OF TEGASEROD FOR IRRITABLE BOWEL SYNDROME AND CONSTIPATION}

Three large, randomized, parallel group, double-blind trials have evaluated the effectiveness of tegaserod ( $2 \mathrm{mg}$ or $6 \mathrm{mg}$ b.d.) vs. placebo in patients with irritable bowel syndrome and constipation from the Western hemisphere. ${ }^{5-7}$ The treatment phase of each trial lasted 12 weeks. Nearly 3000 patients were included in these clinical trials. Unlike most previous studies addressing the effectiveness of traditional medical therapies in irritable bowel syndrome, the tegaserod trials conformed to the rigorous clinical study design recommendations of the ROME committee, a group of international experts on functional gastrointestinal disorders. ${ }^{8}$

The primary end-point for the three pivotal trials was the treated subjects' global assessment of the relief of irritable bowel syndrome symptoms. To determine the effect of tegaserod or placebo on the subjects' global assessment, patients were asked to consider how they had felt in the past week with regard to their irritable bowel syndrome, in particular with regard to overall well-being, altered bowel habits and symptoms of abdominal discomfort and pain. In this way, the subjects' global assessment took into consideration the entire constellation of symptoms important in irritable bowel syndrome. Efficacy was based on the subjects' global assessment response obtained in the final 4 weeks of the treatment phase. A series of graded responses was used to assess the effect of tegaserod or placebo on global irritable bowel syndrome symptoms. In addition to the primary outcome measure, a number of specific individual symptoms important in irritable bowel syndrome, including abdominal pain and discomfort, change in bowel habits, satisfaction with bowel habits and relief of bloating, served as secondary outcomes in these three randomized trials.

In these studies, the median age of the study population was 43.7 years, with $90 \%$ being female and $87 \%$ Caucasian. The median duration of irritable bowel syndrome symptoms was 14.4 years. The efficacy of tegaserod vs. placebo on the primary outcome measure of the subjects' global assessment is summarized in Table 1. Each of the trials found that tegaserod led to a statistically significant improvement in the subjects' global assessment compared with placebo. This improvement in the subjects' global assessment was typically seen within a week of initiation of drug
Table 1. Pivotal trials of tegaserod vs. placebo for irritable bowel syndrome with constipation

\begin{tabular}{|c|c|c|c|c|c|}
\hline \multirow[b]{2}{*}{ Reference } & \multirow[b]{2}{*}{ Patients } & \multirow{2}{*}{$\begin{array}{l}\text { Female } \\
(\%)\end{array}$} & \multicolumn{2}{|c|}{$\begin{array}{l}\text { Responders } \\
\text { for primary } \\
\text { outcome }(\%)\end{array}$} & \multirow{2}{*}{$\begin{array}{l}\text { Therapeutic } \\
\text { gain }\end{array}$} \\
\hline & & & Tegaserod & Placebo & \\
\hline $\begin{array}{l}\text { Müller-Lisner } \\
\text { et al. }\end{array}$ & 881 & 83 & 38 & 30 & 8 \\
\hline $\begin{array}{l}\text { Krumholz } \\
\text { et al. }\end{array}$ & 799 & 87 & 46 & 33 & 13 \\
\hline $\begin{array}{l}\text { Novick } \\
\text { et al. }{ }^{7}\end{array}$ & 1519 & 100 & 44 & 39 & 5 \\
\hline
\end{tabular}

therapy. In addition, tegaserod led to a significant and sustained improvement in the subjects' global assessment, compared with placebo, over the duration of the 12-week treatment phase of each study. The sustained nature of the improvement in the subjects' global assessment suggests that tolerance, or tachyphylaxis, to the drug does not develop. Two of the studies included a 4-week observation period following treatment discontinuation. ${ }^{6,7}$ The improvement in the subjects' global assessment observed during treatment decreased after drug discontinuation to similar degrees in patients randomized to tegaserod or placebo. Thus, there was no evidence of 'rebound' in irritable bowel syndrome symptoms following the withdrawal of tegaserod.

These clinical trials also found tegaserod to be well tolerated. The safety profile of tegaserod has recently been confirmed in a 12-month safety trial. ${ }^{9}$ The most common side-effects reported in this trial included diarrhoea $(10 \%)$, headache $(8 \%)$, abdominal pain $(7 \%)$ and flatulence $(6 \%)$. As a consequence of these pivotal trials, tegaserod is currently approved by the US Food and Drug Administration for the treatment of women with irritable bowel syndrome and constipation.

\section{TEGASEROD: RECENT INTERNATIONAL STUDIES}

A number of recent international studies have offered new insights into the role of tegaserod for patients with irritable bowel syndrome. Documentation of efficacy in non-Caucasian populations can be found in a randomized, controlled, 4-week treatment trial from China in over 500 patients (mean age, 39 years; $82 \%$ females) with irritable bowel syndrome and constipation. This trial found that tegaserod, $6 \mathrm{mg}$ b.d., was significantly 
more effective than placebo in improving the subjects' global assessment of overall irritable bowel syndrome symptoms. ${ }^{10}$ Furthermore, tegaserod was more effective than placebo in improving individual symptoms, including abdominal pain, bloating and constipation. Overall, tegaserod was well tolerated, with the three most commonly reported side-effects being diarrhoea, abdominal pain and dizziness (each reported in less than 3\% of those randomized to tegaserod).

Further clinical information from Asia and the Pacific Rim can be gleaned from the Zelmac Asia-Pacific (ZAP) study. This large randomized controlled trial found tegaserod, $6 \mathrm{mg}$ b.d., to be significantly more effective than placebo for both global and individual symptoms in patients with non-diarrhoea irritable bowel syndrome. ${ }^{11}$ In addition to confirming the effectiveness of tegaserod in an Asian population, the ZAP trial also found that tegaserod may offer an option in patients who do not fulfil the criteria for irritable bowel syndrome and constipation alone or irritable bowel syndrome and diarrhoea alone, i.e. alternators. Unfortunately, as a result of the study design, it was not possible to perform a subgroup analysis to address the efficacy of tegaserod in only those with irritable bowel syndrome and alternating constipation and diarrhoea.

Further evidence that irritable bowel syndrome patients, other than those with irritable bowel syndrome and constipation, may respond to tegaserod comes from a 12-week, randomized controlled trial including more than 600 patients (mean age, 44 years; $86 \%$ females) with non-diarrhoea irritable bowel syndrome from northern Europe [Tegaserod Nordic trial (TENOR)]. This trial found that a greater percentage of those treated with tegaserod $6 \mathrm{mg}$ b.d. than with placebo experienced overall satisfactory relief of their irritable bowel syndrome symptoms using a binary outcome measure. ${ }^{12}$ Like the ZAP study, the TENOR study suggested that tegaserod benefitted irritable bowel syndrome patients who did not have diarrhoea as their primary bowel complaint. Another interesting finding from this study was that patients with a disease duration of less than 10 years were more likely to respond to tegaserod than those with irritable bowel syndrome for more than 10 years. The therapeutic gain for the primary end-point over placebo for those randomized to tegaserod with a disease duration of less than 10 years was $10-26 \%$, compared with $5-15 \%$ for the total study population, over the 12-week treatment period. In this study, diarrhoea was the most commonly reported adverse event with tegaserod (tegaserod 9.2\% vs. placebo $1.3 \%$ ).

A recent open-label study from Latin America (LATAM) evaluated the natural history of irritable bowel syndrome after the withdrawal of tegaserod therapy. ${ }^{13}$ All patients with irritable bowel syndrome and constipation (mean age, 49 years; 92\% females; $48 \%$ Hispanics) received 4 weeks of open-label therapy with tegaserod $6 \mathrm{mg}$ b.d. Eighty-two per cent (553/ 678 ) of patients experienced overall symptom relief with tegaserod using a binary 'satisfactory relief' outcome measure. Following the open-label treatment period, 544 patients with irritable bowel syndrome and constipation were randomized to receive continued tegaserod or withdrawal from tegaserod. Although only $10 \%$ of patients who remained on tegaserod suffered a recurrence of their irritable bowel syndrome and constipation symptoms, $67 \%$ of those who were withdrawn from tegaserod therapy experienced a symptomatic recurrence by the end of the 8-week withdrawal period (Figure 1). The mean time to symptom recurrence after withdrawal of tegaserod was 21 days. Similar findings

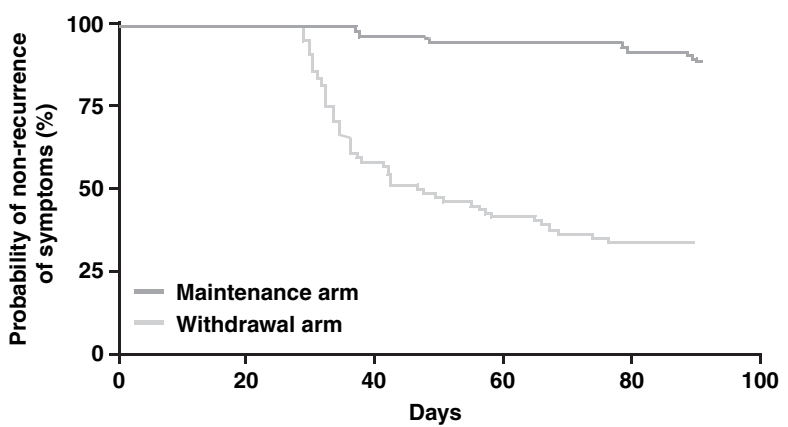

Figure 1. Effect of tegaserod withdrawal or continuation in irritable bowel syndrome and constipation (IBS-C). ${ }^{13}$

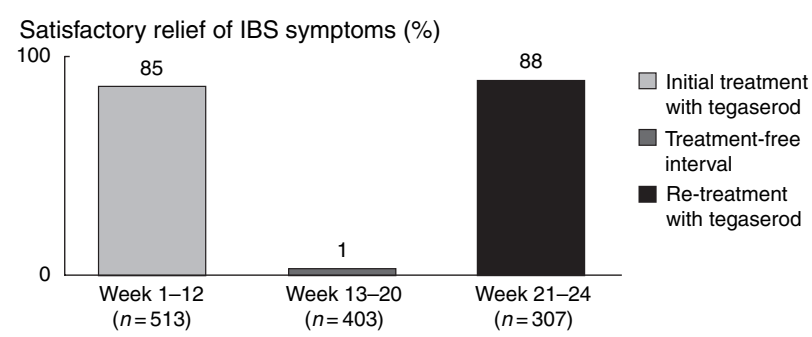

Figure 2. Re-treatment was as effective as initial treatment with tegaserod for irritable bowel syndrome and constipation (IBS-C). ${ }^{15}$ 


\begin{tabular}{lllll}
\hline Efficacy variable & Sex & Pre-treatment & Post-treatment & $P$ value \\
\hline Abdominal & Male & $93.7 \%(74 / 79)$ & $15.5 \%(11 / 71)$ & 0.0001 \\
pain/discomfort & Female & $91.4 \%(32 / 35)$ & $16.7 \%(5 / 30)$ & 0.0001 \\
Straining & Male & $91.1 \%(72 / 79)$ & $15.5 \%(11 / 71)$ & 0.0001 \\
& Female & $82.4 \%(28 / 34)$ & $26.7 \%(8 / 30)$ & 0.0001 \\
Stool frequency & Male & $4.4 \pm 10.19$ & $9.52 \pm 10.07$ & 0.0001 \\
& Female & $5.86 \pm 24.83$ & $8.0 \pm 7.92$ & 0.148 \\
Urgency & Male & $3.8 \%$ & $57.7 \%$ & 0.0001 \\
& Female & $20 \%$ & $56.7 \%$ & 0.002 \\
\hline
\end{tabular}

Table 2. Efficacy of tegaserod in male and female patients with irritable bowel syndrome and constipation from Pakistan ${ }^{16}$ were reported in a study of comparable design recently conducted in the UK. ${ }^{14}$

In a study from Germany, including over 500 patients with irritable bowel syndrome and constipation (mean age, 52 years; $72 \%$ females), patients were initially treated with tegaserod, $6 \mathrm{mg}$ b.d., for 12 weeks. ${ }^{15}$ During this initial treatment phase, $85 \%(436 / 513)$ of patients with irritable bowel syndrome and constipation responded to therapy with tegaserod using a binary 'satisfactory relief' outcome measure. This was followed by a 4-8-week withdrawal phase. As in the LATAM and UK studies, the majority of patients suffered a recurrence of their irritable bowel syndrome symptoms following the withdrawal of tegaserod. The withdrawal phase of the study was then followed by a 4-week re-treatment period. Of the patients with irritable bowel syndrome and constipation who participated in the re-treatment phase of the study, $89 \%$ (274/307) responded to a second course of tegaserod (Figure 2).

An open-label study from Pakistan provides some insight into the potential utility of tegaserod in males with irritable bowel syndrome and constipation. ${ }^{16}$ This study, which included 117 patients (mean age, 37.5 years; 81 males and 36 females), found that participants from both genders experienced significant improvements in abdominal pain/discomfort, straining and urgency with tegaserod. Men also experienced a significant improvement in weekly stool frequency with tegaserod (Table 2). Clearly, more information from high-quality studies is needed in order to determine the utility of tegaserod in males with irritable bowel syndrome, but these preliminary data are promising.

\section{CONCLUSIONS}

Studies from around the world continue to demonstrate the efficacy and safety of tegaserod in ethnically diverse populations of patients with irritable bowel syndrome and constipation. The data discussed above have helped to shed light on a number of clinical management issues involving the use of tegaserod in irritable bowel syndrome patients. Although preliminary studies are encouraging, confirmation of the efficacy in men with irritable bowel syndrome and constipation and in irritable bowel syndrome patients with alternating diarrhoea and constipation is necessary before recommending the routine use of tegaserod in these special populations. Furthermore, important questions remain with regard to the efficacy of tegaserod when given for longer than 12 weeks, and whether treatment with this drug reduces overall health care utilization and costs.

\section{REFERENCES}

1 Brandt LJ, Bjorkman D, Fennerty MB, et al. Systematic review on the management of irritable bowel syndrome in North America. Am J Gastroenterol 2002; 97: S7-26.

2 Gershon MD. Serotonin and its implication for the management of irritable bowel syndrome. Rev Gastroenterol Disorders 2003; 3(Suppl. 2): S25-34.

3 Chey WD. Tegaserod and other serotonergic agents: What is the evidence? Rev Gastroenterol Disorders 2003; 3: S35-40.

4 Camilleri M. Review article: tegaserod. Aliment Pharmacol Ther 2001; 15: 777-89.

5 Muller-Lissner S, Fumagalli I, Bardhan KD, et al. Tegaserod, a 5-HT4 receptor partial agonist, relieves symptoms in irritable bowel syndrome patients with abdominal pain, bloating, and constipation. Aliment Pharmacol Ther 2001; 15: 1655-66.

6 Krumholz S, Tangh J, Schmitt C, Heggland J, Shi Y, Ruegg PC. The 5-HT4 receptor partial agonist tegaserod improves abdominal bloating and altered stool consistency in irritable bowel syndrome. Gut 1999; 45(Suppl. V): A260 (Abstract).

7 Novick J, Miner P, Krause R, et al. A randomized, doubleblind, placebo-controlled trial of tegaserod in female patients suffering from irritable bowel syndrome with constipation. Aliment Pharmacol Ther 2002; 16: 1877-88.

8 van Zanten SJOV, Talley NJ, Bytzer P, et al. Design of treatment trials for the functional gastrointestinal disorders. In: Drossman DA, ed. Rome II: The Functional Gastrointestinal 
Disorders, 2nd edn. McLean, VA: Degnon Associates, 2000: Chapter 11.

9 Tougas G, Snape WJ Jr, Otten MH, et al. Long-term safety of tegaserod in patients with constipation-predominant irritable bowel syndrome. Aliment Pharmacol Ther 2002; 16: 1701-8.

10 Lin SR, Zhou LY, Liu XG, et al. Tegaserod provides rapid, effective relief of abdominal pain/discomfort, bloating and constipation in Chinese patients with constipation-predominant irritable bowel syndrome. Gastroenterology 2003; 124 (4 Suppl. 1): A137(Abstract).

11 Kellow J, Lee OY, Chang FY, et al. An Asia-Pacific, double blind, placebo controlled, randomised study to evaluate the efficacy, safety, and tolerability of tegaserod in patients with irritable bowel syndrome. Gut 2003; 52: 671-6.

12 Nyhlin H, Bang C, Eisborg L, et al. A double-blind, placebocontrolled, randomized study to evaluate the efficacy, safety, and tolerability of tegaserod in patients with irritable bowel syndrome. Scand J Gastroenterol 2004; 39: 119-126.
13 Uscanga-Dominguez L, Cohen Munoz V, on behalf of the Latin America Investigator Group on Tegaserod. Relapse of symptoms following withdrawal of tegaserod treatment in irritable bowel syndrome with constipation. Gastroenterology 2003; 124(4 Suppl. 1): A571(Abstract).

14 Bardhan KD, Forbes A, Marsden C, et al. Continuous treatment with tegaserod provides improved control of IBS-C symptoms. Gut 2003; 52(Suppl. VI): A93(Abstract).

15 Müller-Lissner SA, Holtman G, Loeffler H, Ruegg P. Tegaserod is effective in the retreatment of irritable bowel syndrome with constipation. Gastroenterology 2003; 124(4 Suppl. 1): A574(Abstract).

16 Shah SHA, Jafri SW, Gul M, et al. An open-label study to determine the efficacy and tolerability of tegaserod in the treatment of constipation-dominant irritable bowel syndrome (IBS-C). Gastroenterology 2003; 124: A533(Abstract). 